\title{
An Analysis of College Students’ Autonomous English Learning Ability under the Network Environment
}

\author{
GAO Jin-chi, JIN Ming-hao (Corresponding Author) \\ Department of English, Yanbian University, Yanji, Jilin Province, China
}

\begin{abstract}
Referring to the questionnaire survey and literature materials, this paper describes the current situation of college students' insufficient autonomous English learning ability and thefactors that influence this ability; it also suggests feasible suggestions under the network environment. Students $(\mathrm{N}=178)$ from different grades, majors, universities and areas responded to a questionnaire survey, and the collected data were analyzed. The results indicate that complex external environment and insufficient internal subject cognition influence college students' autonomous English learning ability. Finally, this paper suggests that a good network environment is necessary for autonomous learners to enhance insufficient autonomous English learning ability and interaction, continuous thinking and cultural introduction are also indispensable to develop this ability.
\end{abstract}

Keywords: college students, autonomous English learning ability, network resources

\section{Introduction}

With the rapid development of new media technology in China, a variety of new forms of English study have been presented in recent years, such as mobile applications, Weibo accounts (Chinese version Twitter) and Wechat official accounts. While in the past, there were only a few English websites provided for English learners in the field of English study. Generally, network resources for English study have become more mobile and diverse. Moreover, the popularization of advanced technology increases English learners' (especially college students') access to English and can enhance their autonomous English learning ability. In light of these abundant network resources, new questions emerge of how these resources can be used effectively and which specific resources college students actually need so as to improve their autonomous English learning ability.

JIANG (2010) mentioned that the researches on studying autonomous English learning abilities have been carried out since 1980s. It developed to a new point in 1990s and meanwhile, has been emphasized in the following years. In this way, it is widely recognized as a significant project of acquiring the second language to further discuss the mode of autonomous English learning ability and to search for a feasible approach to improve college-student autonomous English learning ability.

Ministry of Education enacted "The Requirement for College English Teaching” in 2004, which emphasized dominant status of college students in teaching process, enabling them to autonomously choose

GAO Jin-chi (First Author), Undergraduate student, Department of English, Yanbian University.

JIN Ming-hao (Corresponding Author), Ph.D, Associate Professor, Department of English, Yanbian University. 
suitable learning materials that they actually need and to develop themselves to the direction of personalized and autonomous study. With the help of computer network system, autonomous English learning has gone with the tide of college and university's English teaching reform, symbolizing that the reform has been implemented successfully. That colleges and universities in all areas have widely applied multimedia network technology provided English teaching process with a variety of network teaching resources and tremendous lively learning forms.

\section{Theoretical Background}

\section{Definition of Autonomous Learning Ability}

Holec (1981) defined autonomous learning ability as "an ability of mastering our willingness to study on our own”. He believed that there are five important aspects of this ability, including identifying learning targets, learning contents and learning progress, selecting learning strategies, monitoring learning process, and evaluating learning effects. What's more, Dickinson (1995) and Holec (1981) argued that learners being their own masters means that they are completely capable of shouldering responsibility for their own study, identifying learning targets and selecting materials, adopting suitable learning approacheand correctly evaluating learning outcomes. Students' autonomous learning ability is a common goal that all educators want to achieve. If students master specific learning strategies and develop the ability to study automatically, they will reap lifelong benefits in this age of constantly upgraded knowledge.

\section{Empirical Studies on College Students' Autonomous English Learning Abilities}

American psychologist J. Flavell raised a concept of recognition in 1976 for the first time, who believed that metacognition, of which the core is the cognition of a certain cognition and also is a kind of cognition and regulation of one's own conceptual work and learning activities possessed by individuals.

Flavell (1976) suggested that there are three categories of metacognition knowledge, first is the individual knowledge, of which some certain characteristics are owned by individuals themselves and others, all as processors in the case of cognition; second is task knowledge, which is mainly about the information quality, task requirements and its purpose; third is strategy knowledge basically about the strategy and effective application.

JIANG (1997) proposed that metacognition is a psychological mechanism which enables people to know more about autonomous learning ability, of which the core is metacognition ability.

Domestically, WANG and GUO (2000) discussed the essence and factors of metacognition, holding the opinion that matacognition activities include three basic factors, metacognition skills, metacognition knowledge and metacognition experience. Individuals could own the capacity to adjust activities of cognition through synergistic effect within those three.

As analyzed above, combined with new network English learning environment and the theory of metacognition, the current status of college students' autonomous English learning abilities in the circumstance of network will be analyzed and some feasible suggestions will be given to improve their autonomous English learning ability. 


\section{Research Design}

\section{Research Questions}

There are three primary aspects of questions in this paper. They are:

What is the current situation of college students' autonomous English learning abilities in the condition of network study?

What are factors which impose restrictions on autonomous English learning abilities in the condition of network study?

What are strategies to enhance college students' autonomous English learning abilities in the condition of network study?

\section{Data Collection and Analysis}

A questionnaire survey with 20 questions written in Chinese was designed after comprehensive browse previous relevant questionnaires, and shared through a Wechat link in SOJUMP, of which seven about metacognition-related knowledge are picked out to illustrate the current status of college students' autonomous English learning abilities under the network environment. 180 responses were received from random college students on the Internet, among whom, 178 responses are valid.

\section{Participants}

The participants in this research were 178 college students from different grades, majors, universities or colleges and areas, ensuring that collected data and analyzed results are impartial, objective and representative. Among them, 46.07\% participants are from English major and53.93\% from non-English major. What's more, survey covers 28 distinct four-year universities or colleges in 16 cities throughout China.

\section{Instrument}

A questionnaire survey was designed to collect data, which mainly contains two sections: questions reflecting the current situation of college students' autonomous English learning abilities and possible causes of deficiency in autonomous English learning abilities.

\section{Result and Discussion}

The current status will be analyzed mainly in two aspects, according to Flavell's (1976) classification of three varieties of metacognition knowledge (individual knowledge, task knowledge and strategy knowledge), contrast between old and new English learning network environment, and the current status of college students using English learning network resources.

\section{Contrast Between Old and New}

Old English learning network environment mainly consisted of English learning websites, which were originated from the rise of college students' online courses. After developing for nearly ten years, these websites have already become relatively mature, and meanwhile covered the shortage of writing and speaking sources. Some organizations (such as Pigai, a website which excels in revising compositions) have already advanced to an English writing platform where it provides functions of feedback and comment on writing.

On contrast, new English learning network environment increases various source-sharing platforms, such as English learning mobile applications, Weibo accounts, Wechat official accounts and video resources. Take 
English learning mobile applications for example, as a production attached to the mobile phone, it owns powerful functions and convenient user experience. Among them, apps about reciting words became the representation that developed fastest, which not only include all kinds of authoritative dictionaries, but intellectually set up study and review plans to strengthen the memory of words. In the case of listening, lots of apps all provide functions of single-sentence play, loop play and drive-by-wire play. Listening resources cover all sorts of examinations, foreign news and celebrity speech. In addition, oral English training boomed as well, which helps learners practice oral English and rate at any time with the pronunciation evaluation technology within. On the other hand, although functions of Weibo accounts and Wechat official accounts are not as powerful as apps, it is more effective in terms of receiving information, including releasing bilingual news, test-taking skills and on-line courses, especially those popular Weibo accounts about IETLS and TOEFL.

New English learning website is more complicated in the way that different kinds of English learning resources are numerous and mixed. For one thing, the majority of English learning network instruments are not limited in teaching simple knowledge and summarizing skills, but pay more attention to engaging learners' interest. For another, considerable though advantages are, there are some negative views, for example, some lack the veracity of learning resources whereas the others' recreational function is excessive. Moreover, the flooding of the advertisement is another problem. Compared to the former one, however, the advancement of new media and technology renders English learning network environment more complex. English learners' learning capacity would not be strengthened and their attention be distracted unless they utilize those resources well.

\section{“Three Knowledge”}

Individual Knowledge. As for the current status of college students using English learning network resources in the case of individual knowledge, $60.11 \%$ participants have learned English for over 10 years according to the questionnaire survey, as shown in Table 1. While $71.35 \%$ chose 'yes' in the first question as showed in Question 1, which indicates that the majority of autonomous English learners have already basically perceived the level of their own autonomous English learning abilities. Besides that, diverse activities done with the Internet is also included in the survey as shown in Question 2. Through investigation, the majority of interviewees (70.22\%) would surf the Internet for more than two hours every single day while $34.83 \%$ chose to chat with friends and play games, $36.52 \%$ watch movies or series and $16.85 \%$ read news. The remaining students only $11.80 \%$ would perform autonomous English leaning. All above extremely reveals that the time for college students to use network to perform autonomous English learning could not be much less.

Table 1

\begin{tabular}{|c|c|c|c|c|}
\hline No. & Questions & Yes & \multicolumn{2}{|l|}{ No } \\
\hline 1 & $\begin{array}{l}\text { You clearly know the merits and drawbacks of your } \\
\text { autonomous English learning ability. }\end{array}$ & $71.35 \%$ & \multicolumn{2}{|c|}{$28.65 \%$} \\
\hline \multirow{5}{*}{2} & \multirow{5}{*}{ What do you usually do with the Internet every single day? } & \multicolumn{3}{|c|}{ Options } \\
\hline & & \multicolumn{2}{|c|}{ Chat with friends and play games } & $34.83 \%$ \\
\hline & & \multicolumn{2}{|c|}{ Watch movies or series } & $36.52 \%$ \\
\hline & & \multicolumn{2}{|c|}{ Read news } & $16.85 \%$ \\
\hline & & \multicolumn{2}{|c|}{ Produce autonomous English study } & $11.80 \%$ \\
\hline
\end{tabular}


Task Knowledge. On the other hand, in terms of task knowledge, $65.17 \%$ deemed that there is abundance of network English learning resource while only less than 15\% could list 5 to 10 English learning websites, among whom only 3 interviewees could name over 10. It thoroughly manifests that current college students know less about network autonomous English learning because the majority of them reckoned that mass of network English resource is only an assumption according to their common sense. Furthermore, when being asked to choose indispensable resource of autonomous English learning, more than half of interviewees reckoned that it is necessary to be provided with vocabulary resource (88.76\%) and grammar theory resource (78.65\%) in terms of performing autonomous English learning, which shows that how importantly the majority of English learners perceive English foundation. 44.94\% held the opinion that it is indispensable to possess the "communicate with teachers or peers", which indicates that autonomous learners lack the communication and interactive consciousness of learning English. For the rest of them, 21.35\% thought that it is vital to be offered “original English books or English websites”. All above clearly shows that for one, most of autonomous learners lack the sensitiveness of utilizing original English textbooks and for another, they still focus on the basis of English learning in the case of task knowledge about autonomous English learning, as shown in Table 2.

Table 2

Task Knowledge

\begin{tabular}{|c|c|c|c|}
\hline No. & Questions & Options & \\
\hline \multirow{6}{*}{3} & \multirow{6}{*}{$\begin{array}{l}\text { Which one do you think is indispensable when } \\
\text { processing autonomous English learning? } \\
\text { [MOACA }]\end{array}$} & English dictionaries or other vocabulary resource & $88.76 \%$ \\
\hline & & Grammar and other language theory resource & $78.65 \%$ \\
\hline & & Communicate with teachers or peers & $44.94 \%$ \\
\hline & & Original English books or English websites & $21.35 \%$ \\
\hline & & Suitable English language environment & $29.85 \%$ \\
\hline & & No clue & $9.88 \%$ \\
\hline
\end{tabular}

Note. MOACA: Mark out all correct answers.

Strategy Knowledge. In the aspect of strategy knowledge, first the usage of network learning resource by autonomous learners was investigated, such those as domestic and overseas English websites, English learning applications, Weibo accounts and Wechat official accounts as well as radio programme. The data shows that 96.35\% used English learning applications, and among them, 26.12\% utilized Weibo accounts and Wechat official accounts about English study, indicating that college autonomous English learners get used to new network English learning environment well and use more of the latest network resource. Only 3.93\%, however, had more access to overseas English learning website, according to which much less availability of original English study resource could not be clearer. As Question 4 of Table 3 shown below, most users (94.94\%) go to English learning applications to memorize vocabulary, followed by applications for listening and speaking practice, for test-taking skills and for news reading decreased progressively. It strongly shows that the content of studying English for autonomous learners is mainly occupied by memorizing words and that for some of them, incentive for autonomous English learning is driven by external environment (suitable English language environment). 
Table 3

Strategy Knowledge

\begin{tabular}{llll}
\hline No. & Questions & \multicolumn{2}{c}{ Options } \\
\hline \multirow{4}{*}{4} & $\begin{array}{l}\text { What types of English learning applications do you use } \\
\text { most of time? [MOACA] }\end{array}$ & Apps for memorizing words & $94.94 \%$ \\
\cline { 3 - 4 } & & Apps for listening and speaking practice & $43.82 \%$ \\
\cline { 3 - 4 } & & Apps for news reading & $25.28 \%$ \\
\cline { 3 - 4 } & & Apps for test-taking skills & $36.52 \%$ \\
\hline
\end{tabular}

Note. MOACA: Mark out all correct answers.

\section{Metacognition Experience}

Based on "three knowledge", metacognition experience raised by WANG and GUO (2000) reveals that individual's perception and understanding of relevant situation of those experiences. Only through metacognition experience, individuals could provide relevant information towards present progress of metacognition activities adjusted effectively with certain metacognition knowledge. Investigation on the feasibility of college students, thus, utilizing network resources to perform autonomous English learning, the evaluation of study effect and the situation of phased self-summary and introspection is made. As the result displayed, 73.03\% learners have not thought about whether it is feasible to utilize network resources to perform autonomous English learning while $61.80 \%$ did not make any phased self-summary or introspection. Due to this fact, it indicates that autonomous learners lack continuous recognition and regulation on autonomous English learning and also their awareness of adjusting themselves appeared to be weak during the process of autonomous English learning, as shown in Table 4.

Table 4

Metacognition Experience

\begin{tabular}{llll}
\hline No. & Questions & Yes & No \\
\hline 5 & $\begin{array}{l}\text { You believe that it is feasible to utilize network resources to } \\
\text { produce autonomous English learning. }\end{array}$ & $26.97 \%$ \\
\hline 6 & $\begin{array}{l}\text { When performing autonomous English learning, you make } \\
\text { some certain phased self-summary or introspection. }\end{array}$ & $38.20 \%$ & $61.80 \%$ \\
\hline
\end{tabular}

\section{Metacognition Skills}

Autonomous learning metacognition is in essence a form of study, stressing on self regulation, namely, which individuals autonomously choose from, adjust their study plans, produce self reflection, correct mistakes and control their own learning process, according to ZHOU and SANG (2007). In the survey, 73.03\% autonomous learners to perform autonomous English learning in the process of utilizing network resources, adjusting their own learning approaches. It reveals that most of autonomous learners could make some necessary changes towards cognitive activities on the basis of summarizing their own learning experience. As for the investigation on addressing difficulties in the process of autonomous English learning, only $19.66 \%$ autonomous learners chose to "neglect the difficulty" they encountered, which indicates that a larger proportion of learners recognized the ways to tackle problems, such as "study on my own" (15.73\%), "search for approaches on the Internet” (39.33\%) and "ask peers and teachers for help” (25.28\%). Otherwise, it also shows that the approach 
autonomous learners utilize to tackle the difficulty lacks much interaction, as shown in Table 5.

Table 5

Metacognition Skills

\begin{tabular}{llll}
\hline No. & Questions & \multicolumn{2}{c}{ Options } \\
\hline \multirow{3}{*}{7} & $\begin{array}{l}\text { In the process of autonomous English learning, what } \\
\text { approach you will choose to address the difficulty? }\end{array}$ & Neglect the difficulty & $19.66 \%$ \\
\cline { 3 - 4 } & Study on my own & $15.73 \%$ \\
\cline { 3 - 4 } & & Search for approaches on the Internet & $39.33 \%$ \\
\cline { 3 - 4 } & & Ask peers and teachers for help & $25.28 \%$ \\
\hline
\end{tabular}

As analyzed above, there are some factors which could impose an influence on college students' autonomous English learning ability in the circumstance of old and new network environment. First, the ratio of using latest network autonomous English learning resource tends to be much higher than of overseas original English network resource; second, they pay more attention to English basic knowledge study, including the vocabulary and reading, which is way superficial; third, they lack the interest of culturally internal leading incentive of English and interactive communicating ability of autonomous learning; fourth, their cognitive subject consciousness appears to be weak so that their understanding, adjustment and regulation of their own autonomous English learning activities tend to be not sufficient enough.

\section{Strategies to Enhance College Students’ Autonomous Learning Ability}

\section{Select Network Resource Correctly}

In face of diversified English learning resources, autonomous learners require to spend time selecting appropriate learning materials and processing the variety of available information. In this way, looking through comprehensive content, college students could select network learning resources through searching engine and keyword on the basis of pinpointing learning purpose. Take oral English as an example, instead of learning good sentences of English oral expression on mobile apps every day, if autonomous English learners choose to study British English, they can accordingly look for original English programs on BBC to imitate British pronunciation. At the same time, combined with their own learning foundation and learning ability, autonomous English learners should make some appropriate changes after understanding and digesting the knowledge they learn.

\section{Strengthen the Interaction in the Process of Autonomous Learning}

Compared with mutual competitiveness among scholars in the past, the advent of the Internet provides an open platform, especially under the circumstance of new media, where network learning tools have much more access to the communication among autonomous learners. In some way, peers contribute more to the reformation of learning interest, such as in many English study forums, autonomous learners with the same interest or purpose consist of one group, including those preparing IELTS test online perceived themselves as "Kaoya”, in Chinese which means that a bunch of ducks preparing for the test. Mutual supervision and help contributes to enhanced subject cognition and self awareness as well as regulation.

On the other hand, teachers at college or university shoulder the responsibility to lead and supervise students to enhance their autonomous English learning. School authorities should set up specialized lectures or let corresponding teachers to take in charge to strengthen the understanding of network English learning resources. 
Meanwhile, actively taking part in the interaction with students should also be considered as a part of teachers' obligation.

\section{Lay Emphasis on Continuous Thinking}

The core of the metacognition is continuous cognition of metacognition knowledge. Under the circumstance of "Fast-food Culture" in network era, college students exposed to the "Fast-food Culture" for such a long time get used to accepting simple and fractional information, like vocabulary and grammar, rather than those longer paper or obscure knowledge, which extremely relates to most of autonomous English learners' learning incentive. Some autonomous learners, for example, perform autonomous English learning in order to finish homework, pass CET4 or 6, IELTS or TOEFL due to the fact that learns' utilitarianism drive insufficient internal incentive. It is easy for autonomous learners to lack the patience and endurance when studying and even hard to enhance insufficient autonomous learning ability, and thus, spending less and less time on autonomous learning. The biggest benefit of autonomous learning is to strengthen learners' dominant position. Only continuous thinking and study could render autonomous learns complete the process of understanding and accomplishing one foreign language course.

\section{Introduce Cultural Language Study}

Lack of interest in learning the culture of one foreign language will not only limit autonomous learners' learning impetus, but impose a restriction on the efficiency and ability of foreign language acquisition. In terms of studying English, introducing more culture of English speaking countries will deepen the understanding of English language and increase more fun so as to avoid from only focusing on superficial English study, such as the vocabulary and grammar. Internet at present is the main medium around the globe to disseminate the culture, especially under the circumstance of new media, where autonomous learns could use phone to look through foreign news, watch TV shows and series from different countries whenever and wherever so as to get exposed to the latest foreign cultural trends.

\section{Conclusion}

This paper carried out a questionnaire survey on 178 college students from different majors, grades, universities and areas to study factors which impose an influence on autonomous English learners' insufficient autonomous English learning ability. It is found that complex external environment and insufficient internal subject cognition influence college students' autonomous English learning ability. So it is suggested that students should select network resources correctly, strengthen interaction in the process of autonomous learning, carry on continuous thinking and involve in cultural language study in order to enchance autonomous English learning ability.

\section{References}

Dickinson, L. (1995). Autonomy and motivation: A literature review. System, 23(2), 166-167.

Flavell, J. H. (1976). Metacognitive aspects of problem sloving. In L. B. Resnick (Eds), The Nature of Intellgence, (12), $231-236$. Holec, H. (1981). Autonomy and foreign language learning. Oxford: Pergamon Press.

JIANG, W. J. (2010). The necessity of college students' autonomous learning based on network environment and the analysis of learning status. Overseas English, (7), 109-109. 
JIANG, Y. J. (1997). The theory and empirical study of metacognition. Journal of Northeast Normal University Press, 10(2), 144-150.

WANG, L., \& GUO, D. J. (2000). The essence and factors of metacognition. Journal of Psychology, 32(4), 458-463.

ZHOU, Y. E., \& SANG, Q. S. (2007). The summary of domestic and overseas autonomous-learning theory and research. Journal of Hefei Normal College, 25(1), 100-104. 